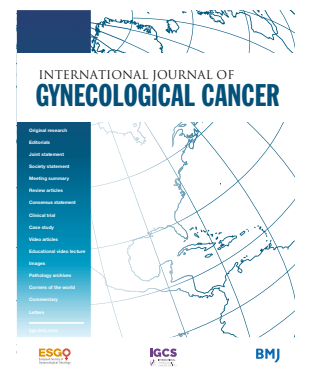

${ }^{1}$ Department of Gynecology Oncology, General University Hospital of Castellón, Castellon de la Plana, Comunitat Valenciana, Spain

${ }^{2}$ Medicine, Universitat Jaume I, Castello de la Plana, Comunitat Valenciana, Spain

Correspondence to Dr Anna Serra Rubert, Department of Gynecology Oncology, General University Hospital of Castellón, 12004 Castellon de la Plana,

Comunitat Valenciana, Spain; serraa@uji.es

Accepted 20 September 2021

\title{
Schauta, an old technique for a new discussion
}

\author{
Anna Serra Rubert (D) ,1,2 Maria Teresa Climent, ${ }^{1,2}$ Antonio Llueca Abella ${ }^{1,2}$
}

\section{SUMMARY}

Radical hysterectomy is the gold standard to treat early stage cervical cancer. Recently published studies have shown that minimally invasive surgery might have lower survival rates than classic open surgery. ${ }^{1}$ In their trial, the authors compared minimally invasive surgery (laparoscopy and robot assisted surgery) with open surgery, but they did not use the classical vaginal approach first described by Schuchardt in 1893 and further developed by Schauta in 1902, and improved by others over time. ${ }^{2}$ Current studies have performed this approach to avoid the use of a uterine manipulator, which with routine use might increase the propensity for tumor spillage, according to some trials. ${ }^{13}$

There are three variations of the Schauta approach: Schauta-Amreich, Schauta-Stoeckel, and CoelioSchauta or laparoscopically assisted radical vaginal hysterectomy, ${ }^{2}$ recently described by Torné et al, ${ }^{4}$ demonstrating high disease free survival and overall survival in a retrospective cohort of patients with early stage cervical cancer.

Our video shows the performance of a modification of the technique, combining the full Schauta operation

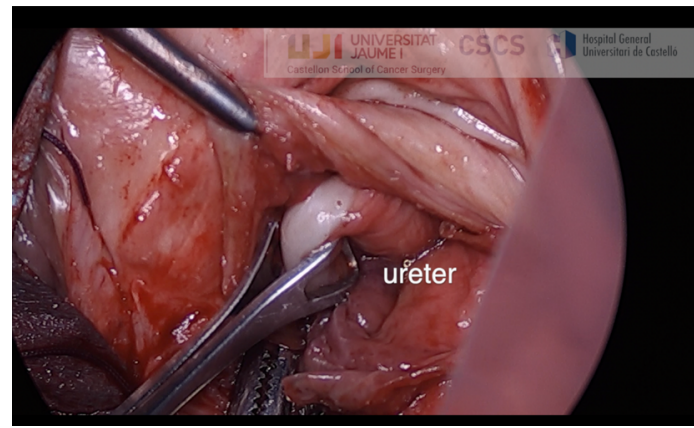

Figure 1 Identification of the ureter: after dissection of the bladder pillar, we can reference the ureters with Babcock forceps to mobilize them cranially to avoid injuries.

with endoscopic lymphadenectomy, published in 1995 by Dargent et al. ${ }^{2}$

Twitter Anna Serra Rubert @annaserrix

Contributors ASR: conception and design, writing of the manuscript, and video editing. ALA and MTC: acquisition of the data and revision of the manuscript for important intellectual content.

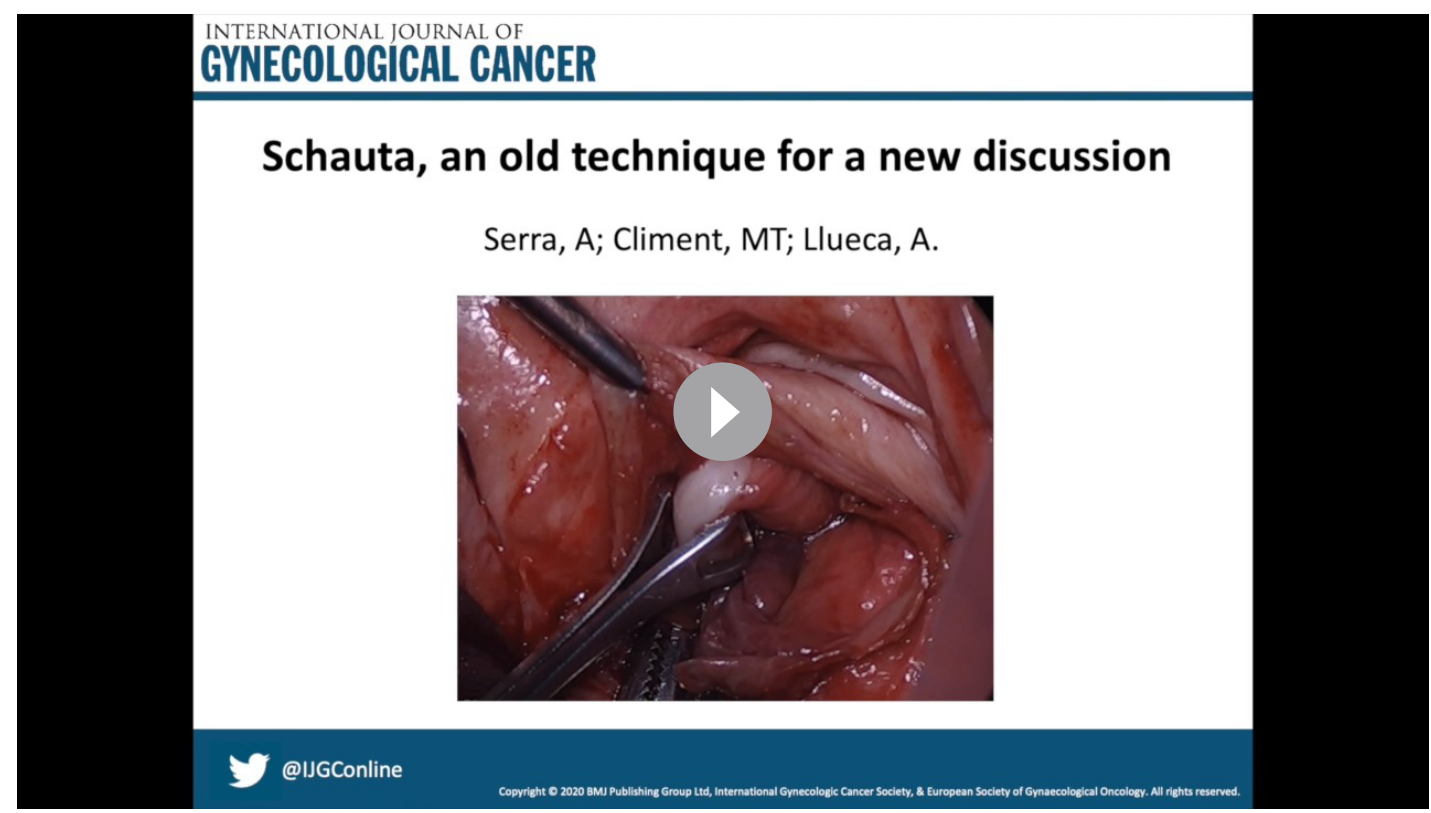

Video 1 Schauta, an old technique for a new discussion 


\section{Video article}

Funding This study was funded by Medtronic University Chair for Training and Surgical Research, University Jaume I (UJI), Castellón, Spain.

Competing interests The authors declare no competing interests.

Patient consent for publication Not applicable.

Provenance and peer review Not commissioned; externally peer reviewed.

Data availability statement There are no data in this work.

ORCID iD

Anna Serra Rubert http://orcid.org/0000-0002-7535-057X

\section{REFERENCES}

1 Ramirez PT, Frumovitz M, Pareja R, et al. Minimally invasive versus abdominal radical hysterectomy for cervical cancer. N Engl J Med Overseas Ed 2018;379:1895-904.

2 Dargent D, Mathevet P. 4 Schauta's vaginal hysterectomy combined with laparoscopic lymphadenectomy. Baillière's Clin Obstet Gynaecol 1995;9:691-705.

3 Chiva L, Zanagnolo V, Querleu D, et al. SUCCOR study: an international European cohort observational study comparing minimally invasive surgery versus open abdominal radical hysterectomy in patients with stage IB1 cervical cancer. Int J Gynecol Cancer 2020;30:1269-77.

4 Torné A, Pahisa J, Ordi J, et al. Oncological results of laparoscopically assisted radical vaginal hysterectomy in early-stage cervical cancer: should we really abandon minimally invasive surgery? Cancers 2021;13:846. 